\title{
Conceptual approach of information rich 3D model about the Terezín Memorial
}

\author{
Pavel Hájek, Karel Jedlička, Martina Vichrová, Radek Fiala \\ University of West Bohemia, Univerzitní 8, 30614 Pilsen, Czech Republic \\ gorin@kma.zcu.cz, smrcek@kma.zcu.cz, vichrova@kma.zcu.cz, \\ fialar@kma.zcu.cz
}

\begin{abstract}
Looking at the concept of the virtual model of Terezin Memorial, the model consists of two main parts: the geometric 3D model which depicts the place and the lexical base of data which describes the history of Terezin, mainly during the II. World War.

Taking a closer look, the heterogeneous nature of existing both analogue and digital documents about the history leads to use a content management system (CMS). CMS is used, together with a relational database, for the lexical data. Each document in CMS has its unique identifier, identifier of a place to which is referred to and two dates referring to a time period. The spatial part of the Terezin model consists of detailed models of all historically valuable buildings and constructions. These models are complemented with less detailed models of the rest of buildings and constructions in the Terezin town.
\end{abstract}

Both lexical and spatial part of the virtual model is filled up with large amount of data. Therefore it is crucial to build such a method of (both lexical and spatial) data selection, which is fast and serve relevant information to the user. Whereas well known one dimensional data indexes can be used for descriptive data, situation is a bit more complex in 3D, where common geographic (two dimensional) data indexes cannot be used. In 3D, size of bounding box (BB) of each potentially portrayed object is calculated, based on the observer position, its view direction and the distance from the object. When the size of BB of each object is calculated, different level of detail (LOD) of each object can be displayed. Different LODs are used also in two dimensional maps, where they are used for creation of a scale dependent map, but there is again principal difference between $2 D$ and $3 D$. While in $2 D$ always just one LOD at a time is portrayed in the map, objects closer to the observer are displayed in higher detail then farther ones in 3D. It leads to a situation, where objects are displayed in different LODs in one $3 D$ scene. This issue poses a major challenge to a creation of a multi-scale 3D model, because different LODs have to share major shape (at least footprints and heights). Moreover the virtual model has to be also time aware, therefore each piece of information in the database has to have a time period for which it is valid.

\section{Introduction - investigation of purposes of 3D modeling}

The topic of 3D modeling of cultural heritage objects is nowadays widely spread. There is possible to find out a lot of projects dealing with this topic, but the purpose or utilization of 
such projects can be different. There is a schema in figure 1 showing examples of a use of 3D models of cultural heritage objects (taken from Jedlička et al. (2012)).

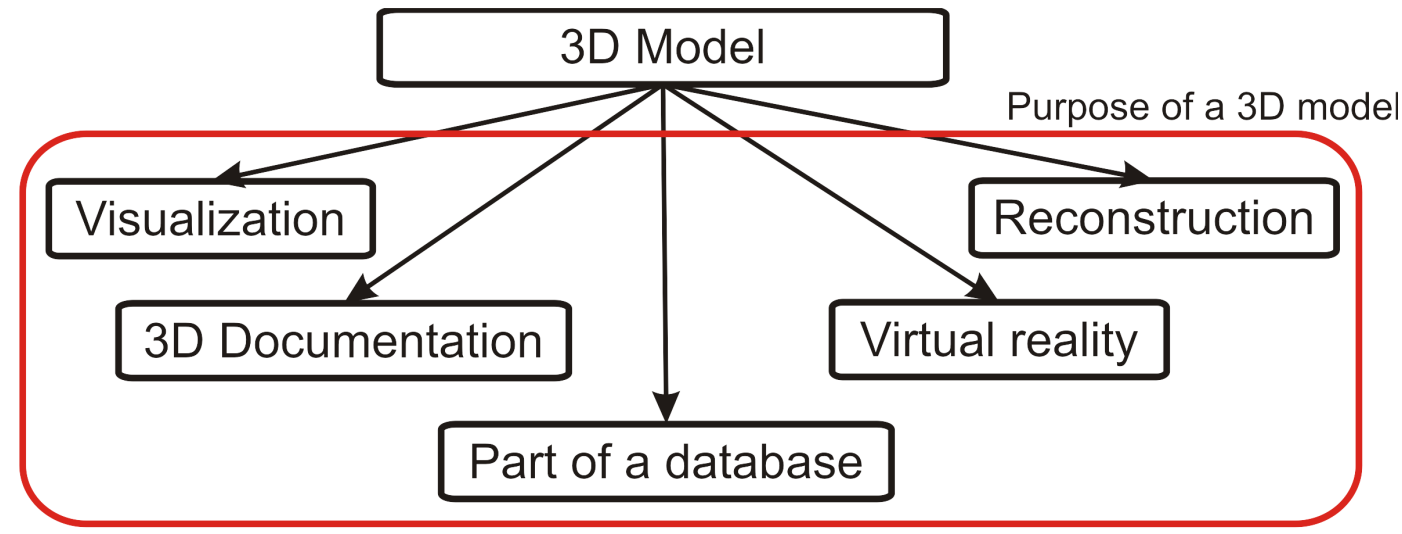

Figure 1: Examples of possible purposes of 3D model in heritage preservation (derived from Jedlička et al. (2012))

A short summary of purposes of $3 \mathrm{D}$ cultural heritage models is shown below (derived from Jedlička et al. (2012)):

- Visualization - the most frequented usage of such models. It is for the purposes of presentation of objects, increasing of accessibility of cultural heritage objects to the public (e.g. through the internet). See examples in Miyazaki et al. (2002), Foni et al. (2010) or Angelini et al. (2011).

- 3D Documentation - a model can be used as a reference for a documentation about the object of interest with an advantage of spatial determination. See examples in Angelini et al. (2011). 3D model as a part of a database - connecting a 3D model to a database means creating of information system about cultural heritage. It's the main purpose for these models, because the collected spatial data can be used not only for the form of presentation. The model and the created database can be also connected to other relevant databases about the object of interest (usually county or national level databases). See examples in Durdag \& Batuk (2011) or in Yan \& Limin (2011),

- Virtual Reality - allows creation a 3D scene, in which the user can interact. See example in Damala et al. (2013)

- Reconstruction - a model persist the appearance of the object in time, so it can be used as a reference for reconstruction or restoration of the damaged objects, objects which don't exist anymore or for the preservation of the contemporary appearance of an object. See examples in He (2011) or in Lin et al. (2011).

A similar point of view at this issue is depicted e.g. in Scopigno et al. (2011). It is said in this reference that the main purposes of $3 \mathrm{D}$ models is for $3 \mathrm{D}$ visualization, for studying artwork and as a medium stored in a database allowing to map, analyze, index, retrieve and compare such a model. This is handful particularly for cultural heritage researchers, archaeologists and curators.

Our approach consists of interconnecting a 3D visualization and a content management system 
(CMS) in order to build an information rich model and particularly to allow interactive querying on buildings and places in the Terezín Memorial for purposes of getting information about the situation of this site at the period of World War Two.

\section{Object of the Case study - the Terezín Memorial}

The fortress of Terezín was constructed between the years 1780 and 1790 by the orders of the Austrian emperor Joseph II in the north-west region of Bohemia. It was designed to be a component of a projected but never fully realized fort system of the monarchy, another piece being the fort of Josefov. By the end of the 18th century, the facility was obsolete as a fort due to changing paradigm of warfare. In the 19th century, the fort was used to accommodate military and political prisoners. However darkest part of the history of Terezin took place during the WW II. The Gestapo took control of Terezín and set up the prison in the Small Fortress (kleine Festung) on June 10 th, 1940 . And the Main Fortress (große Festung, i.e. the fortified town of Theresienstadt) was turned into a ghetto by November $24^{\text {th }}, 1941$. Altought it was presented by the Nazis as a model Jewish settlement to outsiders, in reality it was a concentration camp where over 33,000 inmates died as a result of hunger, sickness, or the sadistic treatment meted out by their captors. In memory of these events, the newly created Czechoslovak government, opened the National Suffering Memorial (later on renamed the Terezín Memorial) in Terezín in 1947. The key mission of the Terezín Memorial, the only institution of its kind in the Czech Republic, is to commemorate the victims of the Nazi political and racial persecution during the occupation of the Czech lands in World War II, to promote museum, research and educational activities, and look after the memorial sites connected with the suffering and death of thousands victims of violence. See more about the history of Terezín Memorial at its Web page http://www.pamatnik-terezin.cz/en?lang= en\&lang=en.

\section{The project "Landscape of memory. Dresden and Terezin as places of memories on Shoah"}

The Terezín Memorial - the memento of Shoah - was selected as the object of the case study in the project with the title: "Landscape of memory. Dresden and Terezín as places of memories on Shoah". The main project goal is to develop and populate a data model suitable for 3D visualization of large-volume spatial data (the whole area of the Terezín town) together with related descriptive data.

The project is a part of the program of cross-border cooperation between the Free State of Saxony and the Czech Republic. It consists of these partners:

- Technische Universität Dresden, MitteleuropaZentrum für Staats-, Wirtschafts- und Kulturwissenschaften (lead partner),

- Terezín Memorial,

- University of West Bohemia (UWB), Geomatics section at Faculty of Applied Sciences.

TU Dresden as the lead partner coordinates the project activities and together with the University of West Bohemia is involved in the developing and determining of a conception, techniques and technologies for creation of 3D models based on various sources such as old maps, plans and other archival documents. The other partner Terezín Memorial has the 
main historical and background knowledge that is crucial to ensure the creation of a realistic $3 \mathrm{D}$ model with necessary descriptive spatial and lexical information. This information will for example help visitors to search for available information about their relatives situated in Terezín during WW II or it will help them to get familiar with the city's appearance in this period.

\section{Data mining of information about the Terezín Memorial}

At the beginning of the project it was necessary to search for available information, documents and materials about the situation in Terezín Memorial during the WW II. There was a need to select proper information from huge amount of collected materials, which are useable for both descriptive data about the life in Terezín ghetto during the WW II and also for 3D geovisualization of the memorial. All original archive materials were kept by the following institutions:

- Terezín Memorial (http://www.pamatnik-terezin.cz),

- State Regional Archive in Litoměřice (http://www.soalitomerice.cz/en),

- Austrian State Archive in Vienna - Military Archive (http://www.oesta.gv.at),

- Military Historical Archive in Prague as a department of Military Central Archive in Prague (http://www. vuapraha.cz/Pages/VojenskyHistorickyArchiv.aspx).

For example, almost 3000 files (such as digital scans of plans, photos, documents, etc.) have been obtained just from Military Historical Archive.

There are three main sources for modelling 3D objects in this project.

- Plans of buildings, facades and reconstruction plans of buildings. Examples of used plans are in figures 2 and 3 . The plans of interiors were used rarely, because the project goal does not claim for interiors to be modelled (interiors of buildings will not be visualized, besides very few exceptions).

- Plans of fortifications. The plans of the city fortification are very detailed because of its historical importance. Because of the complexity of the plans and a simple geometry of the fortification it has been decided that the main source of spatial information about fortification will be a stereo photogrammetric measurements on current aerial images. Plans are consequently used just for clarification of such fortification parts, whose cannot be acquired from photogrammetry. Furthermore it has been decided that the detail of the fortification will be restricted to the expression of the basic shape of bastions and trenches.

- Technical map of the city Terezín. This map shows the contemporary state-of-the-art of the currently standing buildings in the Terezín.

Obtained plans of buildings are just occasionally in metric rate, more frequently in fathom rate. During a detailed research of those plans, it has been set up a uniform conversion rate between fathoms used in plans and meters. This could be done, because the proportions of buildings were on the same plan in both metric and fathom rate occasionally. But looking at the standardized sizes of fathoms there has not been found out any of them fitting to the calculated one from the plans. 


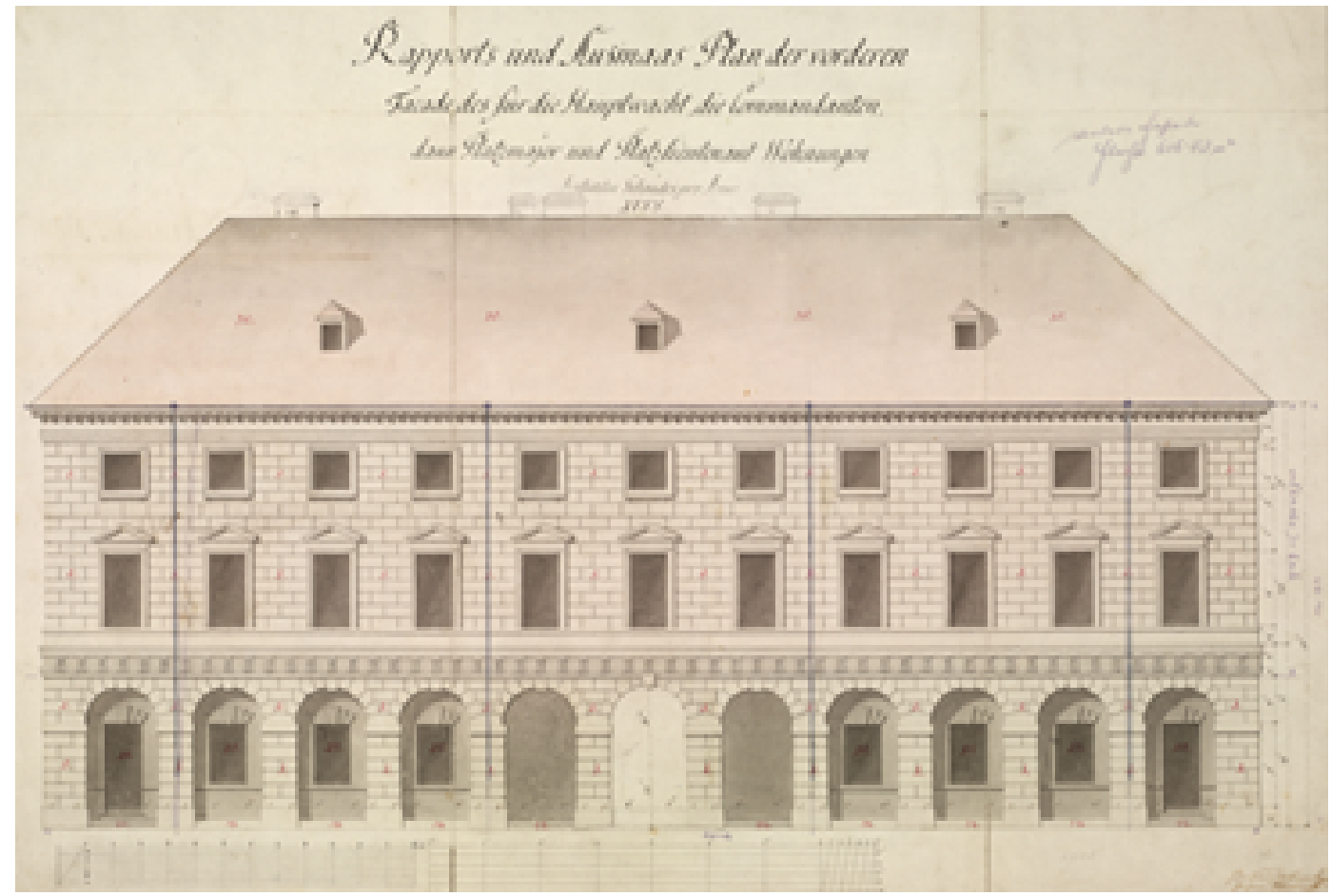

Figure 2: Plan of the building called Knabenheim in Terezín (Military Historical Archive in Prague).



Figure 3: Plan of the Church in Terezín (Military Historical Archive in Prague).

Another issue we were dealing with was that even after a calculated conversion between these rates a lot of proportions didn't fit to the real proportions of the buildings derived from the 
Technical map of the city, which was geodetically surveyed. The difference in proportions was presumably caused by disproportion between the plan and real construction. It is a common phenomenon, that the plan of the building is created and the building itself is built in different way than it is descripted in the plan. These plans are called project documentations, not the representation of the actually built building. In this case, the proportions from the old plans and profiles of the buildings were transformed to the real proportions. This could have been done because the proportions of the standing building were not changed since the World War II.

\section{Conceptual model of Terezín}

The concept of the virtual model of Terezín Memorial consists of two main parts: geometry and related descriptive data. The geometric part consists of 3D models which capture how the Terezín ghetto looked like during the WW II. The descriptive part is based upon structured database of collected documents (descriptive data) which describes the historic information of many particular places in Terezín, again mainly during the WW II. For these main parts of the model have been used two main approaches. A Content Management System for the descriptive data and principle called Level of Detail for the geometric spatial part is used.

Content Management System (CMS) is a tool for handling, together with a relational database, with all the descriptive data (because historical documents of varied characters need to be shown). Each document in CMS has not only its own unique identifier, but also an identifier of a place where the document is referred to and two dates referring to a time period (e.g. the origin and extinction of a building).

As mentioned above, there are a huge number of documents related to events and places in Terezín. But on the other hand, the spatial part of the model is also information-rich. Thus there is a need for dealing with this huge amount of spatial 3D data in the sense of quick querying on data, data visualization and serving relevant data to the user. That's where the principle of various Levels of Detail (LOD) is implemented. The principle comes from the CityGML specification (see OGC (2012)) and it deals with different models for a building, while each model has its own amount of displayed details of the building and the more detailed model is built up on the base of the less detailed model.

The figure 4 shows the use of the conceptual model. It depicts interconnection among a data base (stores links to created 3D models), a content management system (stores collected descriptive data) and an original data (provided from Historical Military Archive). The conceptual workflow is as follows:

On the base of available historical documents and maps which were stored within archives (see chapter Data mining of information about the Terezin Memorial) there were identified objects of interest and Unique IDs were related to them. The ID is created on the base of the designation of rectangular streets system used by Germans in the 1940's. Than on the base of such documents, of the current state of the art of buildings and of the consultancy with the historians from the Terezín Memorial the 3D models were created and stored separately on a disk in a form of kml files, COLLADA respectively. Using a CMS the models are loaded and visualized at kiosk's screen (or via a web client) according the rules of the displayed size of a building (see Figure 6) which are implemented in kml files. 


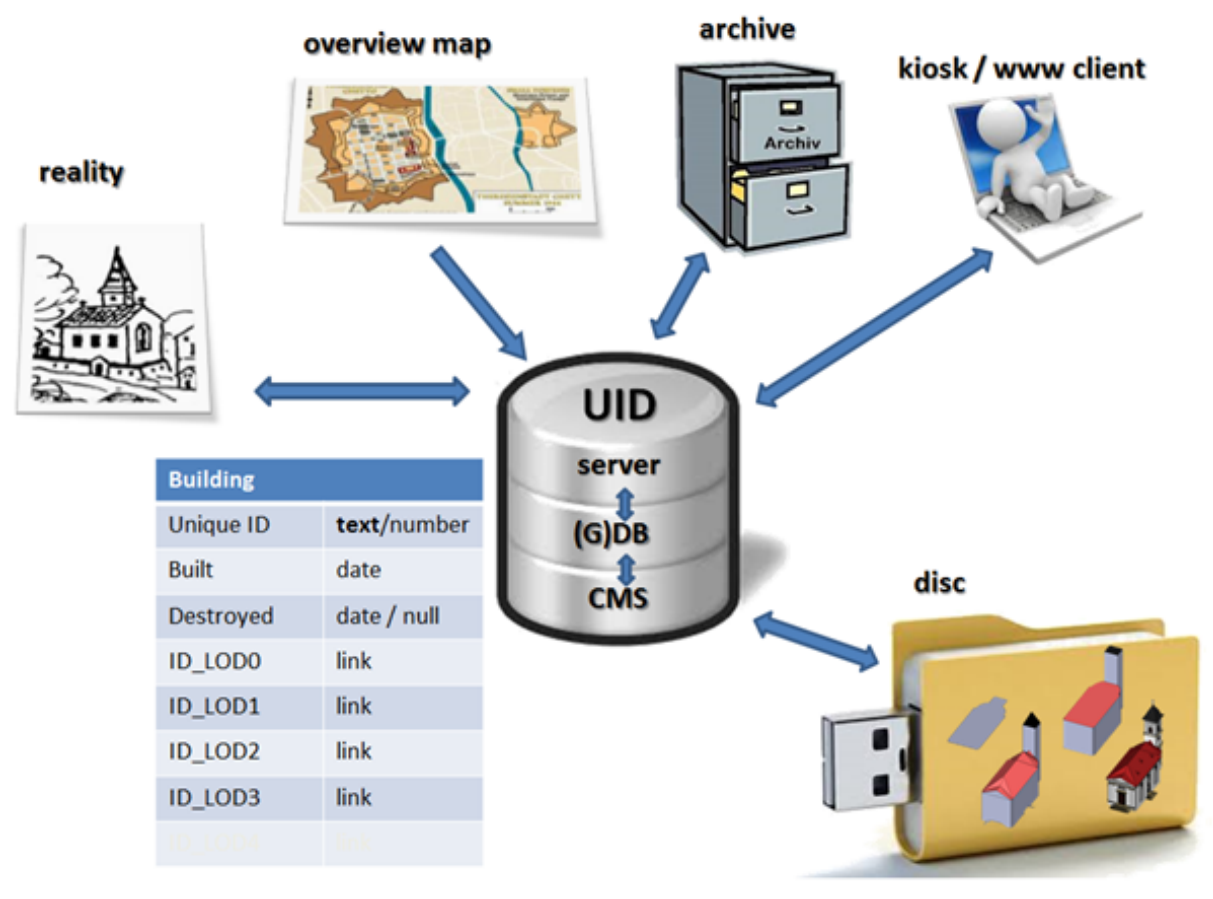

Figure 4: Conceptual approach to creation of 3D information system of Terezín Memorial.

\section{Technical realization of the Terezín Case Study}

As mentioned before, this contribution is based on the work and role of the Geomatics section of the University of West Bohemia in this project. Thus, there will be described technical realization of the spatial 3D model of Terezín Memorial in this chapter, which is the part of the role of UWB in this project.

The first question about modeling of such a model was to decide what tool to use for creating models of buildings. The first idea was to use a Geographical Information System (GIS) as a reference for all spatially referenced data to store them in defined geographic coordinate system. The next workflow had been intended as follow: to create a layer consists of footprints of buildings (refer to LOD0, see further text) and export this layer to Computer Aided Design $(\mathrm{CAD})$ program and use such a program for creating more detailed models. CAD programs have versatile tools for creating 3D models of different objects and they are more suitable for creating a 3D model then GIS programs.

But this approach had met its limitation during the definition of proper proportion of buildings' footprints. The ArcGIS 10.1 had been chosen as a GIS program for creating these footprints. But a problem with a storing of data into a geodatabase had appeared. The problem dealt with perceiving of data accuracy (difference between stored and retrieved proportions of modeled footprints). According to Dive-in section in ArcGIS Resources (2013) this problem is connected with storing coordinates into geodatabase and changing between integer and float type of stored and retrieved numbers. Using such footprints created in this way would cause problems with creation of $3 \mathrm{D}$ models later. Therefore it has been decided to use a CAD system as a reference tool also for creating footprints. 

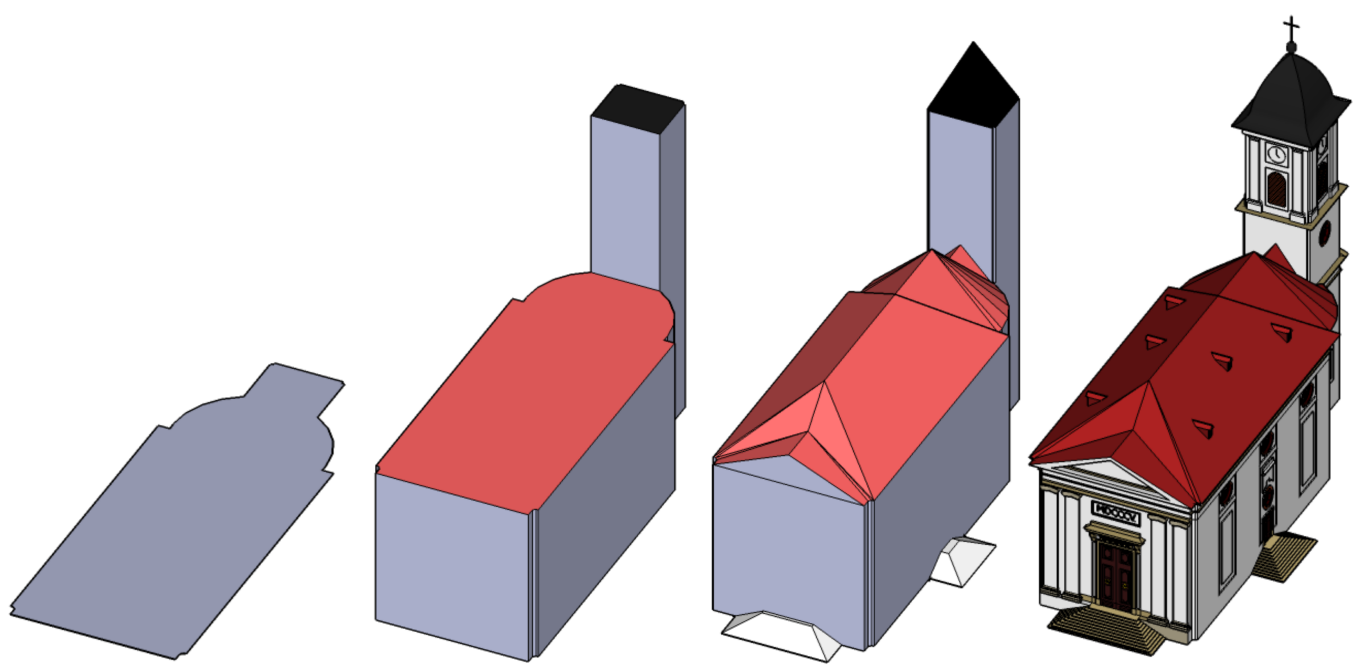

Figure 5: Levels of details from LOD0 to LOD3 on an example of the Church in Terezín (adopted from Janečka et al. (2013)).

Another issue of software for modeling of 3D objects is to contain proper and easy to use modeling tools. In this way a CAD program supposes to have a lot of intuitively usable tools for modeling 3D objects compering with tools which GIS program has for such a thing.

The Trimble SketchUP 8 Pro has been chosen as a CAD program, because it satisfies the conditions of creating the proper proportions of buildings and usability during the process of modeling. And it also has a Georeference Tool, which can georeference an object (building) on the base of Google maps. And moreover the model makers have experiences with this program so it makes an ease, fast and intuitive work with such a tool for them.

On the base of mentioned information it has been decided, that the optimal way for creating all levels of details will be done via Trimble SketchUP software. It is very capable of creating complex 3D objects and when one program for creating all models is used, there is no need for data conversion between data formats so no added possible errors from data conversion are presented. For information about Trimble SketchUP program and creating models in this software, see e.g. Chopra (2011).

Since the beginning of this project it has been known that there will be a huge amount of spatial data. Therefore it has been decided to use a concept of LOD based on LOD in CityGML standard (see OGC (2012)). This concept is made for lowering severity of 3D visualization of objects, which are stored in a spatial base of data. The principle consists of dividing objects into successive component parts. They share the shape of the footprint of the building. It also enables visualization (and also analysis) of the same object depending on different desired LOD.

The example of using this principle is shown in figure 5. There are depicted different LODs of the Resurrection Church placed on the square of Terezín (called just Church in further text). LOD0 (the most left one) consists of the footprint of a building. LOD1 shows the prismatic shape of a building (there is distinguished the nave of the Church and the tower of the Church). LOD2 displays roof-shaped structures and thematically differentiated boundary 

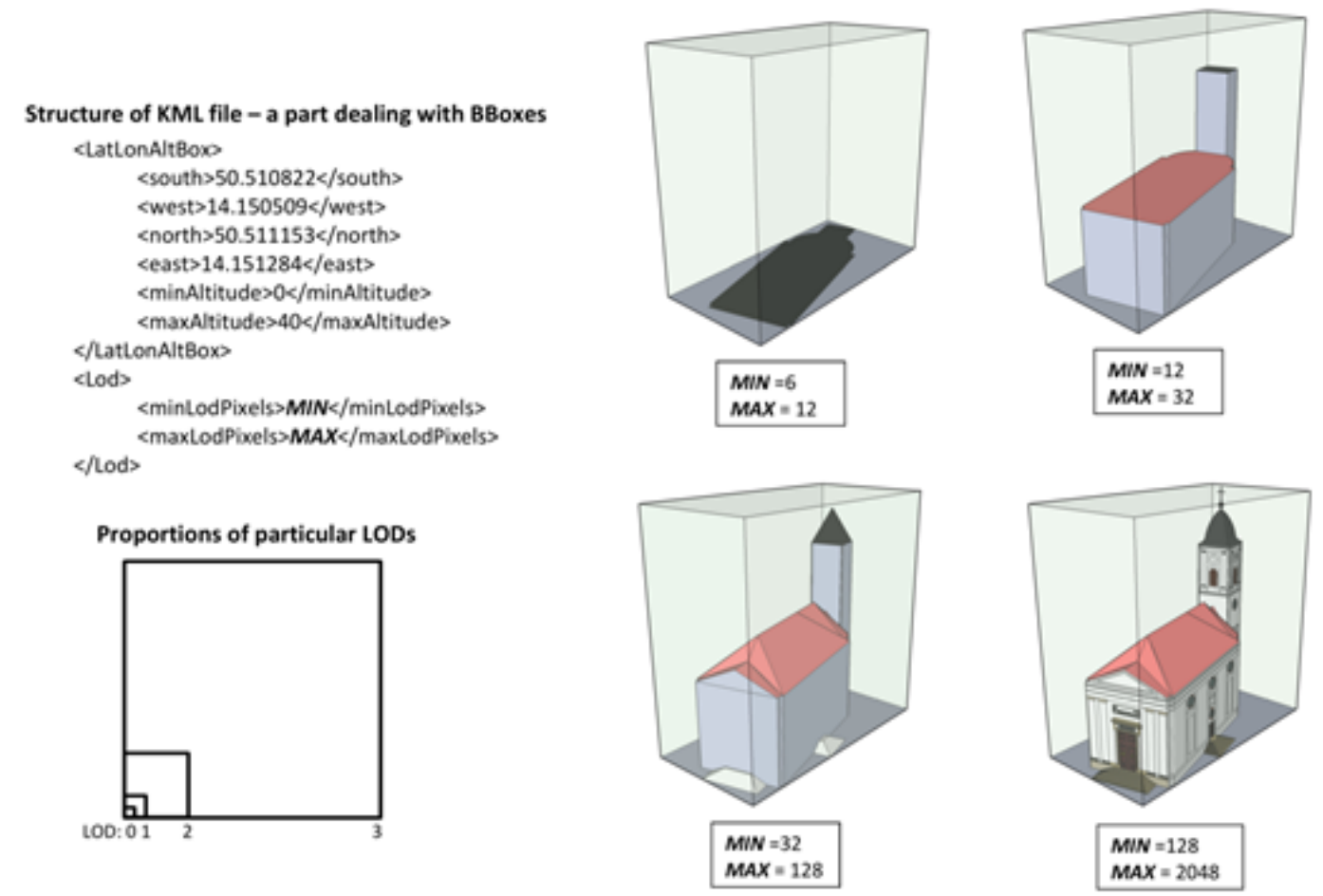

Figure 6: Example of switching LODs based on the pixel size of a bounding box.

surfaces on the exterior shell of a building. LOD3 comprises of architectural models with detailed wall and roof structures. LOD4 is not shown in this picture, because this level of details shows interior of a building and for the purposes of Terezín Memorial LOD4 is not necessary to be modelled (see the beginning of chapter Data mining of information about the Terezín Memorial).

Each LOD of a building is stored in a base of data separately. Using different LODs facilitates so called view- dependent visualization, while the models which intend to be displayed are chosen based on the position, view- direction and distance of the observer. Each building has a bounding box, abbreviated as $\mathrm{BB}$ (BB = minimum volume that encloses a set of objects or data points), which represent the building for purposes of selecting appropriate LOD of the building. The definition of displaying a particular building in a particular level of detail is based on KML built-in features. Switching of different LOD for a building is based on calculated size of a bounding box. When the size of BB in pixels is between MIN and MAX values of $<$ LodPixels $>$ attribute, the $\mathrm{BB}$ with proper LOD of a model is visualized (see figure 6 ; note - in this figure the illustrations of LODs with bounding boxes are in the same size, the real proportions of these bounding boxes are depicted in the left bottom side of this figure). This size of a bounding box is calculated for a position of the observer and then a suitable LOD is selected for displaying according to the size of the bounding box and limits embedded in the model. More information about this KML feature can be found in OGC (2008) or Wernecke (2009).

The principle of using different LODs makes visualization faster. For different view at data, during their visualization, an appropriate model with its suitable LOD is sent to the client 
(i.e. visualized). It means no additional computation for e.g. generalization or loading of huge amount of data is necessary. The example of this view-dependent visualization is depicted in figure 7. In this picture, in the vicinity of an observer, on the right side of the picture, are portrayed very detailed models (LOD3) of the Church and a building called "Knabenheim". Near the observer position, on the left side of the picture, a block of buildings, which is a combination of two levels of details, LOD 2 and LOD3, but less detailed than the previously mentioned buildings, are shown. In the centre of the picture several buildings in prismatic shape (LOD1) are depicted. In the distance is a footprint of another building, which is displayed in LOD0.

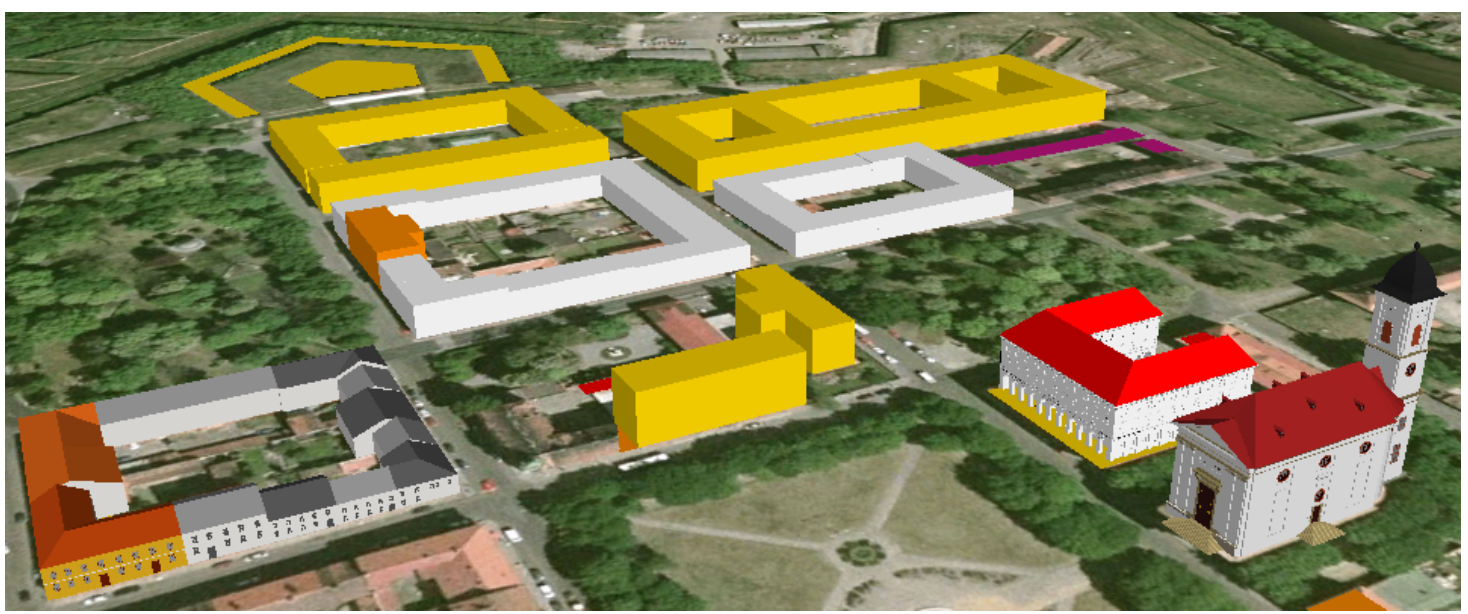

Figure 7: View-dependent visualization of different LODs of buildings in Terezín (adopted from Janečka et al. (2013)).

Just for explanation - as it can be seen in figure 7, buildings are typified in two categories for purposes of the project, the yellow and the grey. It's because the importance of a particular building. In gold category are very important buildings, in grey category are buildings with nearly no importance (related to the purpose of the project). Relevance of a building to a category is based on two aspects. The first is, if considerable events took a place there or significant people lived there (during period of WW II). The second associated aspect is existence of preserved documentation about a place or people. If a building satisfies one of these two aspects, the building is classified as "yellow". The "yellow" is just a temporary category, the final model will be distinguishing between non-important grayscale buildings and important ones - coloured buildings (such i.e., the Church or Knabenheim in the current state of the project).

The process of creation various levels of 3D model is described using the Church as an example. There is a lot of documentation about the church, from which the model can be created. But first of all, just the footprint (acquired from the Technical Map of the city Terezín) is required for LOD0. LOD1 is created by extrusion of footprints into roof heights measured by stereo photogrammetry. Old plans and archive information are firstly used during the construction of LOD3, where the roof-shape is reconstructed - there it is crucial to deal with unit conversion (see at the end of chapter Data mining of information about the Terezín Memorial). The archive materials are the main source for creating the LOD4 of the building (again, after the unit conversion) - see the figure 8 for reconstruction of the ornament above the front wall of 
the Church. Upper part of the figure 8 shows a scan of the original plan of the Church's front side, lower part is illustration of its virtual model created via Trimble SketchUP. Although level of details 3 is very detailed, the view at such buildings will not be so close. From that reason and because of need of effective work during the modelling process, a certain degree of accuracy or generalization is used (generally speaking for all LODs). It is not necessary to model every detail, it is important to capture the substantiality of a building or its part. This is shown in the picture 8 , the detail of drawing of flowers is simplified so as the drawing on abutments on the sides.

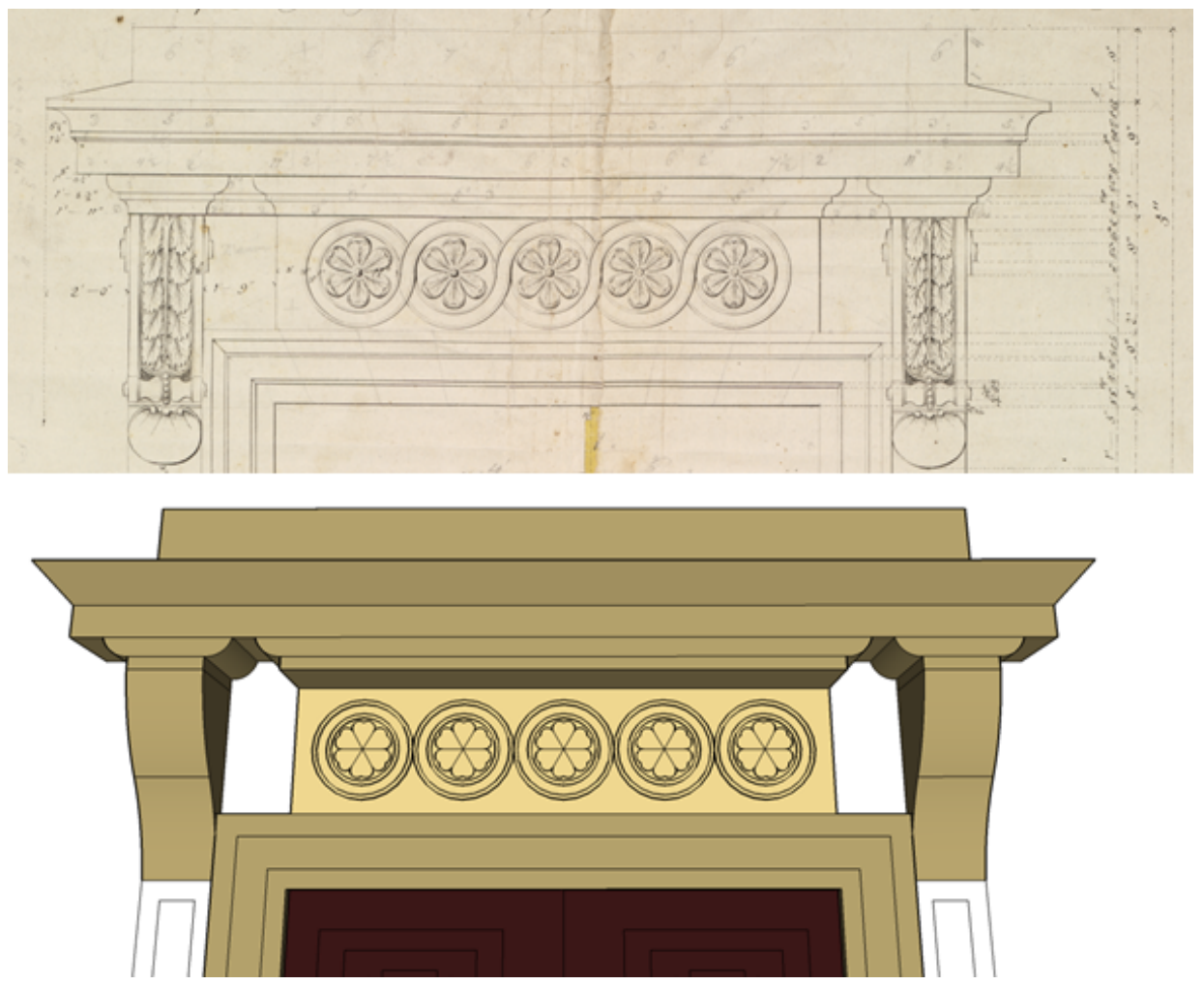

Figure 8: Plan and model of a detail on the front wall of the Church (Military Historical Archive).

The next step of the workflow is to connect descriptive data to each particular 3D representation of a building or a place. It is realized using unique CMS identifiers stored in the KML models of buildings. The development of the data structure used for storage of descriptive data into a content management system is also a part of the project "Landscape of memory. Dresden and Terezín as places of memories on Shoah", but the technical realization is not described in this article.

\section{Discussion}

There has been used a way how to deal with 3D models repository. This way is based on using a PostGIS as a database which stores just links to proper kml files (containing 3D models) stored in a different repository. There had been thought about another way of dealing with storing and retrieving 3D models. The other thought way is based on the storing 3D models 
directly in PostGIS via its native data types. But it would take longer time for visualization of $3 \mathrm{D}$ objects, because the $\mathrm{kml}$ files would need to be populated with collada files (data type for storing 3D models directly in PostGIS) on-the-fly. Therefore the actually used way seems to be more reasonable then the second one descripted above. The other thought way was using the CityGML for conceptual modelling. Even though these discussed ways are equal in the sense of dealing with 3D objects, the selected solution has been chosen on the base of already created Google Earth plug-in obtained from the project partner TU Dresden. This solution is based on mentioned GE plug-in and open Content Management System called Plone CMS and a web client for visualization of data in CityGML is not sufficient.

\section{Summary}

This contribution shows an approach to visualize of large-volume data in a case Study at the Terezín Memorial. First it introduces motivation of the project "Landscape of memory. Dresden and Terezín as places of memories on Shoah". Afterwards the concept that has been used for model creation was presented and explained. Further the paper describes the used technical solution and realization in detail. On the basis of created model there will be realised a result of the project, which will be an interactive information system displaying 3D models of Terezín Memorial containing the multimedia historical content. The model of Terezín will be available at Terezín Memorial's premises and installed on interactive kiosks and alternatively it will also be presented online on the web.

\section{Acknowledgement}

Authors were supported by projects:

- "Landscape of memory. Dresden and Terezín as places of memories on Shoah", reg. number 100110544, that was approved for financing within the Objective 3 - Support of Cross-Border Cooperation 2007-2013 between the Independent State of Saxony and the Czech Republic.

- "NTIS - New Technologies for the Information Society", European Centre of Excellence, CZ. 1.05/1.1.00/02.0090, European Regional Development Fund (ERDF).

- NeoCartoLink - Supporting the creation of a national network of new generation of Cartography, CZ.1.07/2.4.00/31.0010, OPVK.

\section{References}

[1] Angelini, M., G., Constantino, D., Milan, N. (2011) 3D and 2D documentation and visualization of architectural historic heritage, XXIIIth CIPA Sympozium, Prague, Czech Republic, September 12 -16, 2011, available at http://cipa.icomos.org/fileadmin/ template/doc/PRAGUE/008.pdf

[2] ArcGIS Resources (2013) Spatial references, 12. 2. 2013, Esri, available at <http:// resources.arcgis.com/en/help/main/10.1/index.html\#//006z0000000n000000>, cited [18.5.2013]

[3] Belai, E., Jedlička, K. (2012), 3D model památkově chráněného areálu na základě kombinace jeho geodetické a architektonické dokumentace [3D model of heritage protected area 
HÁJeK, P. et al:: Conceptual approach of information Rich 3D MOdel ...

based on a combination of surveying and architectural documentation], Pilsen, Bachelor thesis. University of West Bohemia in Pilsen, Faculty of applied science, available at <http://gis.zcu.cz/studium/ZaverecnePrace/2012/>

[4] Chopra, A. (2011) Google SketchUp 8 For Dummies, John Wiley \& Sons, ISBN 978-0470-91682-7

[5] Damala, A, Schuchert, T., Rodriguez, I., Moragues, J., Gilleade, K., Stojanovic, N. (2013) Exploring the Affective Museum Visiting Experience: Adaptive Augmented Reality (A2R) and Cultural Heritage, International Journal of Heritage in the Digital Era, Volume 2, Number 1 / March 2013, pages 117-142, ISSN 2047-4970

[6] Durdag, U., M., Batuk, F. (2011), Implementation of campus cultural heritage database with support of photogrammetry, XXIIIth CIPA Sympozium, Prague, Czech Republic, September 12 - 16, 2011, available at <http://cipa.icomos.org/fileadmin/ template/doc/PRAGUE/044.pdf >

[7] Foni, A., Papagiannakis, G., Magnenat-Thalmanna, N. (2010) Taxonomy of Visualization Strategies for Cultural Heritage Applications, ACM Journal on Computing and Cultural Heritage, Vol. 3, No. 1, pages 1-21, ISSN 1556-4673

[8] He, Y. (2011), Re-Relic/Yuanmingyuan: an effektive practice in virval restoration and visual representation of cultural heritege, XXIIIth CIPA Sympozium, Prague, Czech Republic, September 12 - 16, 2011, available at <http://cipa.icomos.org/fileadmin/ template/doc/PRAGUE/071.pdf $>$

[9] Military Historical Archive in Prague, Plans Collection of fortress Terezín and other military facilities in Terezín and around 1780 - 1943. Plans of Terezín. sign: 1-17/a1/630000, 2-1305/14/617000, 2517/n38/672200.

[10] OGC (2008) OGC KML, Open Geospatial Consortium, version 2.2.0, Publication Date: 2008-04-14, available at <http://www.opengeospatial.org/standards/kml>

[11] OGC (2012) OGC City Geography Markup Language (CityGML) En-coding Standard, Open Geospatial Consortium, version 2.0.0, Publication Date: 2012-04-04, available at <http://www.opengeospatial.org/standards/citygml>

[12] Janečka; K., Čada, V.; Fiala; R., Hájek, P.; Jedlička; K., Ježek; J., Strycová; J., Vichrová, M. (2013) The 3D model of Terezín Memorial, In: Proceedings of GI2013. Dresden. ISSN: $1801-6480$

[13] Jedlička, K., Hájek, P., Bobek, K. (2012) Geographic passport of publicly open heritage site - Case study at the castle Kozel, DCH2012, International CODATA Conference on Digital Cultural Heritage, Conference Handout

[14] Lin, Y., Ch., Wu, T., Ch., Hsu, M., F. (2011), The digital reconstruction of a large - scale construction simulated by using 3D laser scanning technology - a brick kiln's chimney in Kaohsiung city of Taiwan as an example, XXIIIth CIPA Sympozium, Prague, Czech Republic, September 12 - 16, 2011, available at <http://cipa.icomos.org/ fileadmin/template/doc/PRAGUE/164.pdf>

[15] Miyazaki, D., Ooishi, T., Nishikawa, T., Sagawa, R., Nishino, K., Tomomatsu, T., Takase, Y, Ikeuchi, K. (2002) The Great Buddha Project: Modelling Cultural Her- 
Hásek, P. et al.: Conceptual approach of information rich 3D model ...

itage through Observation, Modeling from Reality The Kluwer International Series in Engineering and Computer Science Volume 640, pp 181-193

[16] Scopigno, R., Callieri, M., Cignoni, P., Corsini, M., Dellepiane, M., Ponchio, F, Ranzuglia, G. (2011) 3D Models for Cultural Heritage: Beyond Plain Visualization, Computer, vol. 44, no. 7, pages 48-55, July 2011, doi 10.1109/MC.2011.196

[17] Wernecke, J. (2009) The KML Handbook - geographic visualization for the Web /Upper Saddle River. ISBN 978-0-321-52559-8.

[18] Yan, H., Limin, C. (2011), 3D-GIS Application in Information Management and Conservation Planning of Historic City, XXIIIth CIPA Sympozium, Prague, Czech Republic, September 12 - 16, 2011, available at <http://cipa.icomos.org/fileadmin/ template/doc/PRAGUE/157.pdf > 